\title{
Free Text Format
}

National Cancer Institute

\section{Source}

National Cancer Institute. Free Text Format. NCI Thesaurus. Code C70764.

A format that does not specify any text properties and does not require pre-established arrangement or organization of data. 